\title{
AUTONOMOUS MINI OBSERVATORY FOR METEOR SPECTROGRAPHY
}

\author{
F. Espartero ${ }^{1,2}$, M. Frías ${ }^{1,3}$, G. Martínez ${ }^{4}$, and A. J. Castro-Tirado ${ }^{2,5}$
}

\begin{abstract}
We present a new autonomous system to study meteors' emission spectra based on the image capture with CCDs, wide field cameras and a holographic diffraction gratings. The equipment contains two spectrographs with different configurations, so that unique and complementary images of the same event can be captured. The system is formed by an Autonomous Mini Observatory, which holds the two spectrographs, connected to a weather station and two computers where the data obtained nightly is stored in their hard drives.
\end{abstract}

\section{RESUMEN}

Presentamos un nuevo sistema autónomo para estudiar espectros de emisión de meteoros basado en la captura de imágenes con CCDs, objetivos de gran campo y redes holográficas de difracción. El conjunto del equipo dispone de dos espectrógrafos con diferentes configuraciones, de forma que permiten capturar imágenes del mismo evento, distintas y complementarias. El equipo está conformado por un Mini Obervatorio Autónomo, que alberga los dos espectrógrafos, conectados a una estación meteorológica y a dos ordenadores, para almacenar en sus discos duros los datos obtenidos cada noche.

Key Words: meteorites, meteors, meteoroids

\section{INTRODUCTION}

The Autonomous Mini Observatory for spectrography has been developed to accommodate the two spectrographs responsible for capturing the emission spectra of fireballs and meteors during the process of ablation when they enter the terrestrial atmosphere. It is located in the Andalusian Astronomy Observatory ( $\left.37^{\circ} 24^{\prime} 54^{\prime \prime} \mathrm{N}, 3^{\circ} 57^{\prime} 12^{\prime \prime} \mathrm{W}\right)$, near Alcala la Real (South of Spain) at 1030 metres above sea level.

The spectrographs can capture bright meteors with an apparent magnitude over -2, although it is more effective with fireballs, with an apparent magnitude below -4 . Through the combined action of both spectrographs, with different technical configurations, several spectra of the same meteor can be obtained. Unlike the low resolution video techniques for meteor detection (Espartero \& Madiedo, 2016), this technique can yield greater detailed results.

\footnotetext{
${ }^{1}$ Observatorio Andaluz de Astronomía, 23688 La Pedriza, Alcalá la Real, Jaén, Spain (espartero@astroalcala.es).

${ }^{2}$ Instituto de Astrofísica de Andalucía, CSIC, Apt. 3004, P.O. Box, 18080 Granada, Spain.

${ }^{3}$ School of Physics, University of Bristol, BS8 1 TL Bristol, United Kingdom.

${ }^{4}$ Departamento de Ingeniería de la Construcción y Proyectos de Ingeniería. Campus de Fuentenueva, Universidad de Granada, 18071 Granada, Spain.

${ }^{5}$ Departamento de Ingeniería de Sistemas y Automática (Unidad Asociada al CSIC), Universidad de Málaga, 29010 Málaga, Spain.
}

\section{EQUIPMENT}

The whole system is composed of the Mini Observatory, a weather station for astronomy and the spectrographs, and is connected to two PCs. All the data is downloaded daily to the hard drives, for subsequent study and analysis (Espartero et al, 2017).

The two spectrographs are located inside a sealed enclosure adequately protected against the weather. The first spectrograph has a 1.4 Megapixel Atik 314L+ CCD with a monochrome sensor Sony ICX285AL ExView with $1392 \times 1040$ pixels. This CCD is attached to a Sigma $4.5 \mathrm{~mm} \mathrm{f/2.8} \mathrm{EX} \mathrm{DC}$ HSM objective for a Nikon mount, which provides a $120^{\circ}$ field of view. $250 \mathrm{~KB}$ images are obtained with this spectrograph.

The second spectrograph, shown in Figure 1, consists of an Atik $11000 \mathrm{CCD}$ with $4008 \times 2672$ pixels with a $37.25 \mathrm{~mm} \times 25.7 \mathrm{~mm}$ Kodak KAI 11000 monochrome sensor. It is attached to a $50 \mathrm{~mm}$ focal length Nikon objective f/1.2 with a field of view of $46^{\circ}$, which takes $2.2 \mathrm{MB}$ images. Over both objectives we have a 1000 lines per mm holographic diffraction grating.

A PVC module serves as protection for the system. The cameras and their optics are inserted inside two PVC tubes, which anchor the spectrographs and allow them to be handled without damaging or altering the equipment. The tubes are covered by float glass and connected to a heating tape which protects the spectrographs at low temperatures. 

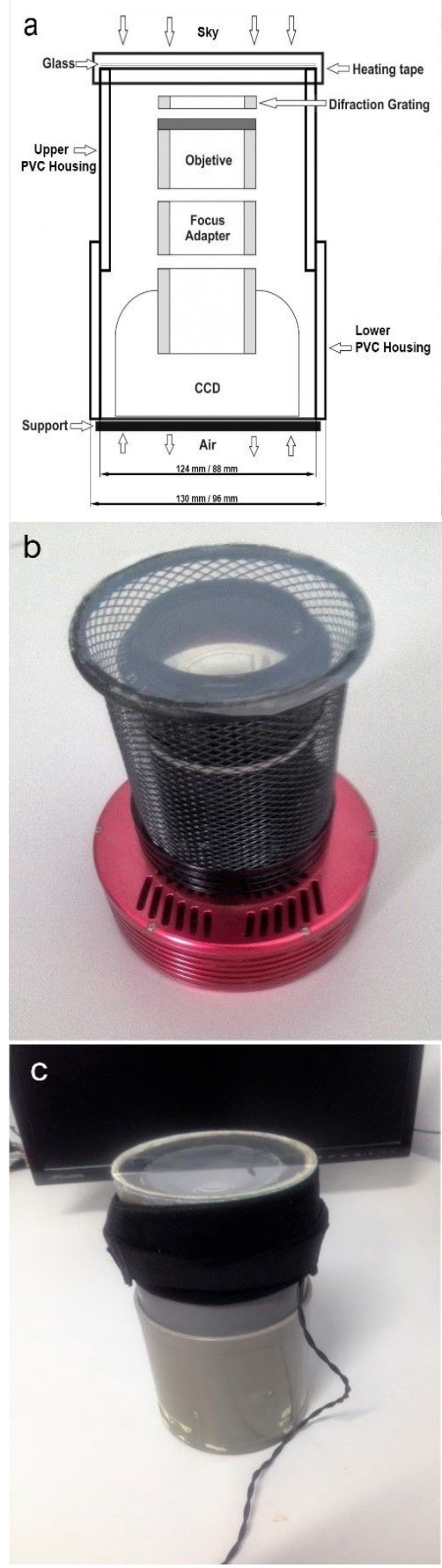

Fig. 1. Functional design of the two spectrographs (a). Spectrograph composed of the Atik 11000 CCD + connection + Nikon $50 \mathrm{~mm} \mathrm{f} / 1.2$ objective and diffraction grating with adaptor (b). Spectrograph with protections and heating systems (c)..

This whole set (Figure 2) is inserted into the Mini Observatory which can be operated remotely. Equipped with an automatic sliding roof and several supports where the cameras and other optics are
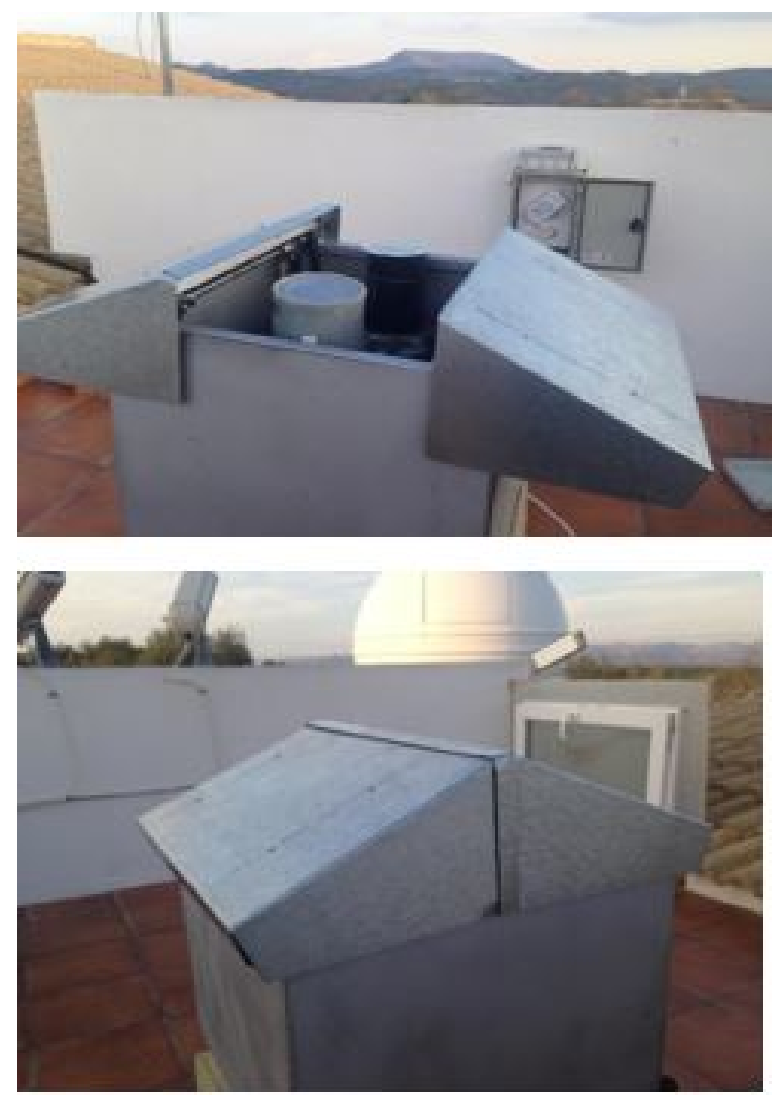

Fig. 2. Autonomous Mini Observatory operating with the two spectrographs inside.

placed, it is connected to a $220 \mathrm{~V}$ electrical current through a power supply which prevents the equipment from failing in case of a power outage.

Connected to the protection module there is a weather station which monitors the sky conditions to determine if they are adequate for the system to work. Measuring the sky brightness, solar radiation rate and cloud rate among other parameters, it sends a signal to the AES to close the sliding roof if said parameters surpass a certain value. The system then enters hibernation mode until the sky conditions improve. The weather station also controls the closing of the roof at sunrise and its opening at sunset, so that the cameras can continue capturing images of the sky and storing them in the PCs overnight.

\section{CONTROL AND ANALYSIS SOFTWARE}

The data stored in the hard drives of the computers is available when a bolide alert is received. The images are then located by time and date. The code used to describe the meteors is $\mathrm{M}$ for meteor, followed by the date (year YYYY, month MM, day DD) and Universal Time (hour HH, minute MM and second SS). 

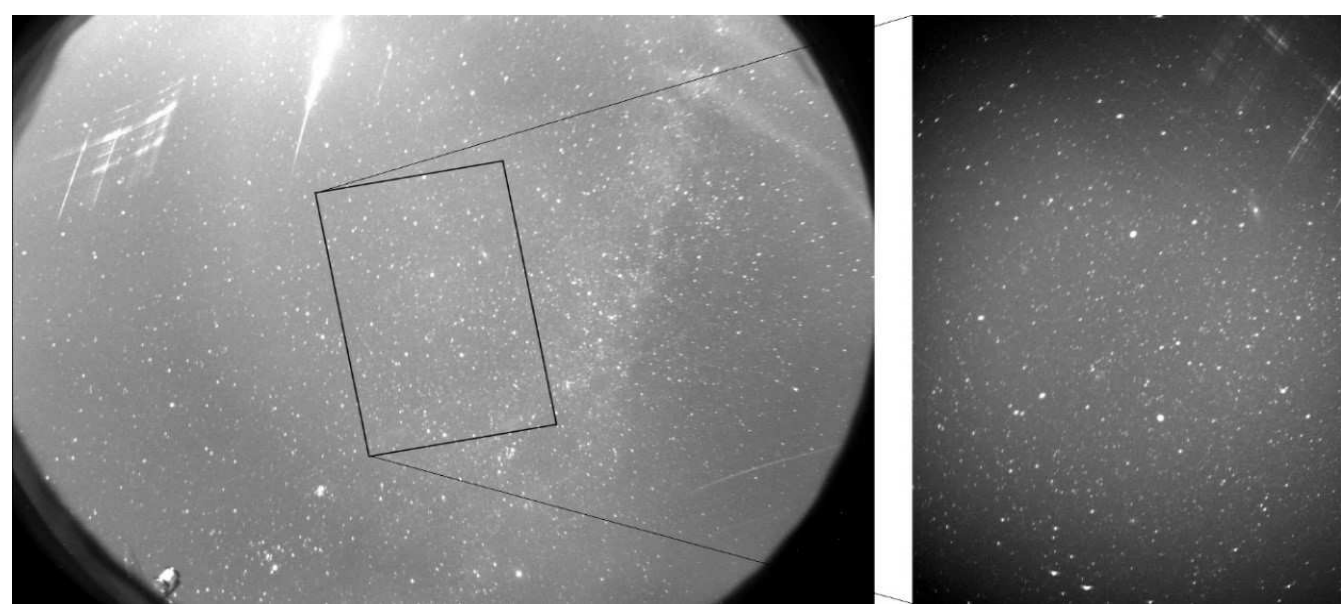

Fig. 3. Image composed of the two images of the spectrum of the meteor M20151118_220605 taken simultaneously with both spectrographs.

The image capture is done with the original software ARTEMI from the CCD Atik manufacturer, in fits format. The image reduction process is done subtracting the previous or following image from the capture we are interested in with the MAXIM DL software.

The quantum efficiency of each CCD is needed to calibrate the spectrum. To that effect, the obtained spectra have this calibration, specific for each CCD.

The main bolide spectra captured by this spectrographic system have been obtained as an intensity profile by comparing the pixel brightness for arbitrary intensities against the number of pixels. These spectra are automatically analysed and calibrated for intensity and wavelength with the CHIMET software (Madiedo et al. 2011a), to identify the main wavelengths with different chemical elements, such as $\mathrm{Na}$, $\mathrm{Mg}, \mathrm{Fe}, \mathrm{Ca}$ or $\mathrm{Cr}$. The analysis of the procedures of this software have been described in Trigo-Rodriguez et al. (2003).

To this end, the cited program used a data base with the main frequencies and emissions typical of meteor spectra. These frequencies have been taken from the NIST Atomic Spectra Database (http://physics.nit.gov/PhysRefData/ASD/ lines_form.html). This way, the software can superpose the theoretical spectral lines with the new lines from the analysed spectrum. Following this, a few known lines from the spectrum are selected, such as $\mathrm{Na}$ and $\mathrm{Mg}$, and the software automatically fixes the different positions of the known theoretical lines.

\section{RESULTS}

Bolide captured simultaneously with both spectrographs. The existing difference between both cap-

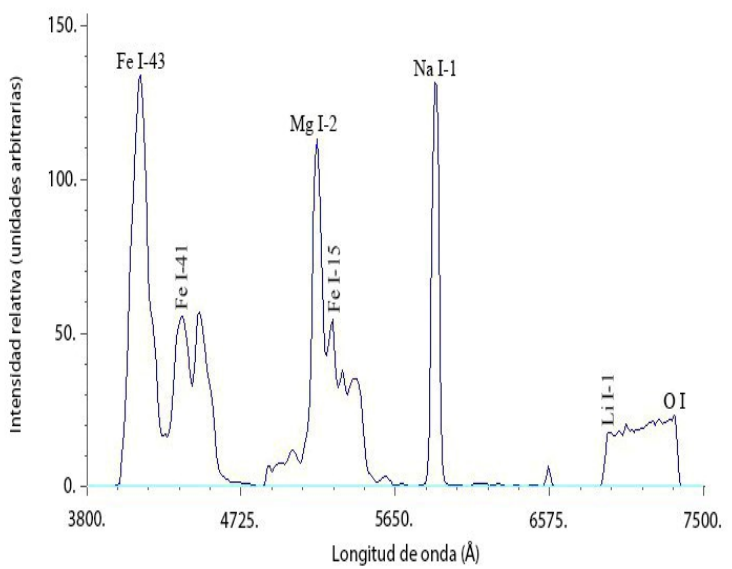

Fig. 4. Image of the emission spectral lines of the bolide M20151118_220605 in wavelength $(\AA)$ against units of relative intensity obtained with the first spectrograph.

tures can be appreciated in the compound image (Figure 3). In the image on the left we can visualize the meteor and its apparent trajectory. In the image on the right, only the spectral traces can be seen, close to the border of the image.

The emission spectra obtained (Figures 4, 5) from the fireball M20151118_220605 have not been satisfactory due to the presence of clouds and the bad atmospheric conditions that night. Nevertheless, two spectra were attained which, although weak, constitute another opportunity to appreciate how the spectrographs can complement each other. Only a comparison of the $\mathrm{Mg} \mathrm{I}-2, \mathrm{Fe} \mathrm{I}-15$ and Fe I-41 triplets can be made. 


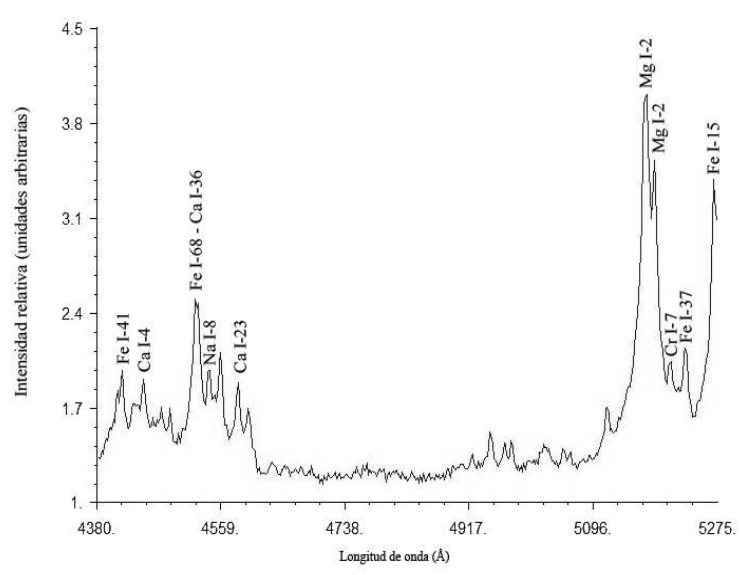

Fig. 5. Image of the emission spectral lines of the bolide M20151118_220605 in wavelength $(\AA)$ against units of relative intensity obtained with the second spectrograph.

\section{CONCLUSIONS AND FUTURE PLANS}

1. The set composed of the Mini Astronomic Observatory, the two spectrographs, the weather station and the computers forms a complete system for the autonomous study of meteor spectrography. Predominantly manually built, several pieces have been assembled to form different devices, which are activated every night to capture the main phenomena related to meteors for our study.

2. The combination of the two spectrographs has allowed us to obtain two different and complementary images of the same object. This has enabled us to contrast and compare the captured images and especially the spectral result obtained.

3. The response of each CCD to the same object can be observed, which is highly useful to compare and gain reliable data for improvement projects in the future.
4. It is intended to develop a new spectrograph which will incorporate a mechanical system (currently under study), which would allow us to capture images with indefinite time intervals, as accurately as possible. For this we have the possibility of including a rotating element which, in a functioning regime, would assure the time intervals with a precision of at least 0.05 seconds. This will enable us to calculate orbital and trajectory data if at least two more stations with the same characteristics are used.

5. We also want to build a new Autonomous Mini Observatory with two equal spectrographs in parallel, with the same technical characteristics and two equal holographic diffraction gratings but with a $90^{\circ}$ orientation with respect to each other. They will have more than 1000 lines per $\mathrm{mm}$. The spectrographs will work simultaneously but with a time difference of 20 seconds between them. In this way, during the image download (dead time), one of them will always be photographing the sky.

Acnowledgements: We want to thank the technical work and help received by Francisco S. Montes Moya. We would also like to thanks the help and collaboration of the M.I. Ayuntamiento de Alcalá la Real and the Excma. Diputación de Jaén.

\section{REFERENCES}

Espartero, F. A. 2013, TFM Univ. Granada

Espartero, F. A. \& Madiedo, J. M. 2016, EM\&P, 118, 81, DOI 10.1007/s11038-016-9491-4

Espartero, F. A. 2017, PhD Thesis, Univ. Complutense Madrid, Spain

Espartero, F. A., et al. 2017, EP\&S, submitted

Madiedo, J. M., et al. 2013, MNRAS, 433, 571

Trigo-Rodríguez, J. M., Llorca, J., Borovicka, J., \& Fabregat, J. 2003, M\&PS, 38, 1283 